\title{
Effect of a Motivational Interviewing-Based Health Coaching on Quality of Life in Subjects With COPD
}

\author{
Hamid Rehman MD, Craig Karpman MD, Kristin Vickers Douglas PhD LP, and \\ Roberto P Benzo MD MSc
}

\begin{abstract}
BACKGROUND: Improving quality of life (QOL) is a key goal in the care of patients with COPD. Pulmonary rehabilitation (PR) has clearly been shown to improve QOL, but is not accessible to many eligible patients. There is a need for alternative programs designed to improve patient well-being that are accessible to all patients with COPD. Our goal was to pilot test a simple, telephone-based health-coaching intervention that was recently shown to decrease readmission among hospitalized COPD patients and stable COPD patients eligible for PR. METHODS: Subjects received a 3-month intervention consisting of 10 health-coaching telephone calls based on motivational interviewing principles. Outcome measures included dyspnea level, measured by the modified Medical Research Council scale, and QOL, measured by the Chronic Respiratory Questionnaire and a single-item general self-rated health status. RESULTS: Fifty subjects with moderate to severe COPD were enrolled in the study. Forty-four subjects $(86 \%)$ completed the study intervention. Dyspnea measured by the modified Medical Research Council score improved significantly after the intervention $(P=.002)$. The domains of fatigue, emotional function, and mastery on the Chronic Respiratory Disease Questionnaire and the single-item QOL question also improved significantly after the 3 months of health coaching $(P=.001, P=.001, P=.007$, and $P=.03$, respectively). Thirty-six (71\%) subjects had a clinically meaningful improvement in at least 1 study end point (either in the severity of dyspnea or a domain of QOL). Thirty subjects (58\%) had an improvement of $\geq 0.5$ points, the minimum clinically important difference in at least 1 component of the Chronic Respiratory Disease Questionnaire. CONCLUSIONS: A telephone-delivered motivational interviewing-based coaching program for COPD patients is a feasible, well-accepted (by both participants and providers), simple, and novel intervention to improve the well-being of patients with COPD. This pilot study provides insight into a possible alternative to a conventional PR program for patients with limited access to that program. Key words: COPD; health coaching; health-related quality of life; health status; mMRC; motivational interviewing; physical status; pulmonary rehabilitation. [Respir Care 2017;62(8):1043-1048. (C) 2017 Daedalus Enterprises]
\end{abstract}

\section{Introduction}

Perception of quality of life (QOL) in COPD is a critical and clinically meaningful outcome, as it matters to the

\footnotetext{
Dr Rehman is affiliated with Pulmonary Medicine, Mayo Clinic Health System, Austin, Minnesota. Drs Karpman and Benzo are affiliated with the Division of Pulmonary and Critical Care Medicine, and Dr Vickers Douglas is affiliated with the Department of Psychiatry and Psychology, Mayo Clinic, Rochester, Minnesota.

This research was supported by the National Institutes of Health research grant R HL114162-02A1.
}

patient and is related to health-care utilization. ${ }^{1,2}$ A 2007 systematic review showed that low health-related QOL was associated with an increased risk of hospitalization and rehospitalization among subjects with COPD. ${ }^{3}$ Both general and disease-specific QOL measures are independently associated with survival in models adjusted by age,

\footnotetext{
Supplementary material related to this paper is available at http:// www.rcjournal.com.
}

The authors have disclosed no conflicts of interest. 


\section{Motivational Health Coaching in COPD}

$\mathrm{FEV}_{1}$, and body mass index. ${ }^{4}$ For that reason, improving perception of health is one of the key goals of COPD care. ${ }^{5}$

Pulmonary rehabilitation (PR) has shown to be effective in improving the perception of health-related QOL among patients with COPD. ${ }^{6-9}$ Unfortunately, PR is not accessible to many eligible patients. Key barriers for enrolling into a PR program include lack of facilities within proximity, poor mobility, absence of transportation, cost of travel, inconvenient timing, and low perceived benefit. ${ }^{10-13}$ Of those patients who do enroll, a substantial number do not complete the full program because of lack of social support, depression/anxiety, illness, and comorbidities. ${ }^{14-16}$ Further, the lack of patient engagement and the following behavior change may explain why the benefits of PR decline to baseline at 6-12 months after program completion. ${ }^{17}$ There is a need for alternative options to PR for patients who do not have access to it.

Telehealth technology, ${ }^{18}$ internet-based selfmanagement programs, ${ }^{19}$ home-based PR programs, ${ }^{20-22}$ and clinic-based exercise counseling ${ }^{23}$ have been evaluated as alternatives to PR for improving health status and dyspnea. While some methods have been effective in improving health status, ${ }^{24,25}$ others have not shown considerable results in symptom improvement, ${ }^{18}$ and overall, alternative programs have not been widely adopted. We recently showed in a randomized clinical trial that health coaching was beneficial in decreasing patient readmission rates and improving QOL when administered after a COPDrelated hospitalization. ${ }^{1}$ In this study, we pilot tested the effect of a simple, low-cost, motivational, interviewingbased health-coaching intervention via telephone on the QOL of stable subjects with COPD.

\section{Methods}

\section{Participants and Recruitment}

All participation was voluntary, and each subject was required to complete a written informed-consent form. The study was approved by the Mayo Clinic Institutional Review Board (Protocol \#11-000356). The target population for recruitment was a convenience sample of subjects receiving out-patient COPD care who were eligible for $\mathrm{PR}$ at a Midwestern tertiary care center (Mayo Clinic) but were not able to come for onsite PR at Mayo Clinic in Rochester, Minnesota. Inclusion criteria were: 1) current or for-

\footnotetext{
Correspondence: Roberto P Benzo MD MSc, Mindful Breathing Laboratory, Division of Pulmonary and Critical Care Medicine, Mayo Clinic, 200 First Street SW, Rochester, MN 55905. E-mail: benzo.roberto@mayo.edu.
}

DOI: $10.4187 /$ respcare. 04984

\section{QUICK LOOK}

\section{Current knowledge}

Pulmonary rehabilitation (PR) has clearly been shown to improve perceived quality of life, but is not accessible to many eligible patients. There is a need for alternative programs aimed at improving patient wellbeing that can be available to everyone. Our goal was to pilot test in out-patients with COPD, and eligible for $\mathrm{PR}$, the effect of a simple, telephone-based healthcoaching intervention recently shown to decrease readmission among hospitalized COPD patients.

\section{What this paper contributes to our knowledge}

A telephone-delivered, motivational, interviewing-based coaching program for COPD subjects was a feasible, wellaccepted (by both participants and providers), simple, and novel intervention to improve the well-being of subjects with COPD. This pilot study provides insight into a possible alternative to a conventional PR program for patients with limited access to that program.

mer cigarette smokers, as determined by social history, of at least 10 pack-years; 2) a diagnosis of COPD; 3) a Global Initiative for Chronic Obstructive Lung Disease (GOLD) II-IV classification based on spirometry in the past 24 months; and 4) eligibility for PR. Exclusion criteria were: 1 ) age $<18$ y, or 2) a non-ambulatory status secondary to a considerable comorbidity. Subjects were recruited April-December 2011, and Figure 1 shows the flow of participants.

\section{Study Intervention}

Details of the training and fidelity to treatment have been published. ${ }^{26}$ The study site had 1 dedicated coach or interventionist, a registered nurse (Mayo Clinic) trained in motivational interviewing. Each encounter, either in person or via telephone, embodied the spirit of motivational interviewing, emphasizing the participant as the expert, the willingness of the coach to listen and understand the participant, and the empowerment of the participants to adopt the behavior they think necessary for them to pursue treatment, even if it's not directly related to their pulmonary condition. Specific instruction on the use of the "Emergency Plan" is in the online repository (see the supplementary materials at http://www.rcjournal.com). The book Living a Healthy Life With Chronic Conditions ${ }^{27}$ was provided to introduce the concept of self-management. Finally, subjects were given a Stamina InMotion Elliptical Trainer (Stamina Products Inc., Springfield, Missouri) to 


\section{Motivational Health Coaching in COPD}

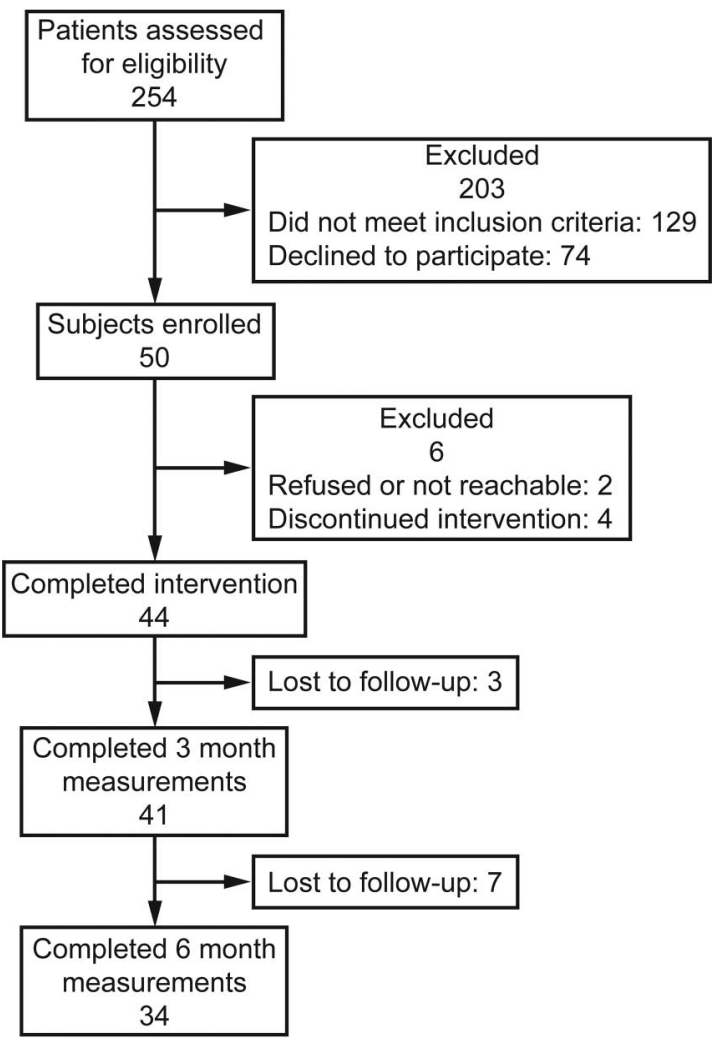

Fig. 1. Flow chart.

use daily (while in a seated position), and instructed on 3 simple upper-extremity exercises to try. The exercise regimen was simple: All participants rehearsed the exercise with the coach and, if they were confident with the exercises and did not have $\mathrm{O}_{2}$ desaturation, bradycardia, or tachycardia during the in-person demonstration, they could choose to participate in the study. Fall precautions were given to all participants. Each subject received 10 healthcoaching telephone calls of approximately $15-$ to 20 -min duration over 3 months (weekly calls during months $1-2$, biweekly calls during month 3 ).

The health coach demonstrated the technique of pursedlips breathing followed by the subject's demonstration and discussion of the breathing technique. Participants were also encouraged to call their coach if they had concerns about worsening symptoms and had to self-initiate emergency medications. The primary care provider of each participant in the intervention was engaged from the first visit and was kept up-to-date by letter. Specifics about the intervention have been published previously. ${ }^{1,26}$

\section{Measures}

Demographic information was collected at the initiation of the study. Dyspnea was measured using the modified Medical Research Council (mMRC) dyspnea scale. ${ }^{28}$ Dis- ease-specific QOL was measured by the Chronic Respiratory Disease Questionnaire ${ }^{29}$; composed by 4 domains: dyspnea, fatigue, emotional, and mastery, and generic QOL were measured using a single-item, general self-rated health status (GSRH) measure that asked: "Overall, how would you rate your health during the past four weeks?" Answers were given on a 5-point Likert scale $(1=$ excellent, 2 = very good, $3=$ good, $4=$ fair, and $5=$ poor). ${ }^{30,31}$ Intervention completion was designated when participants completed 8 of 10 scheduled health-coaching telephone calls.

A post-intervention qualitative evaluation was performed on 16 randomly selected participants, evaluating subject perception of accountability, physical activity level, activity awareness, the value of communication with a coach, and barriers to exercise.

\section{Data Analysis}

Values are presented as mean \pm SD unless otherwise stated. Paired $t$ tests were used to compare pre- and postintervention values. For all tests, $P<.05$ was considered statistically significant. Excellent to poor on the GSRH measure was translated into a 1 to 5 (using the Likert scale) for analysis, with a lower score indicating a better overall health status. Clinically meaningful changes from baseline to post-intervention at 3-month follow-up were defined as a 0.5 -point change for the Chronic Respiratory Disease Questionnaire domains, a 1-point change for the mMRC, and a 1-point change on the GSRH measure.

\section{Results}

We enrolled 50 subjects, 29 (57\%) male, age $68.5 \pm 7.7$ y (mean $\pm \mathrm{SD}$ ), who had moderate to severe disease, and $\mathrm{FEV}_{1} 39 \pm 15$ percent of the reference value. Forty-four subjects (86\%) completed the study intervention (Fig. 1).

The baseline, 3-month (post-health coaching), and 6-month changes for all the measured variables are shown in Table 1. After the health-coaching intervention, fatigue, emotional function, and mastery domains of the Chronic Respiratory Disease Questionairre all had a statistically significant improvement. Overall health status as measured by GSRH also substantially improved. The measure of dyspnea mMRC improved post-intervention and continued to show improvement at 3 and 6 months.

\section{Responder Analysis}

After completion of the coaching sessions, 36 (71\%) participants had a clinically meaningful improvement in at least 1 study end point, either mMRC ( $>1$ point) or a domain of the Chronic Respiratory Disease Questionairre ( $\geq 0.5$ points). Thirty participants $(58 \%)$ had a minimum clinically important difference improvement of at least 1 


\section{Motivational Health Coaching in COPD}

Table 1. Effect of Coaching Intervention on Dyspnea and Quality of Life

\begin{tabular}{|c|c|c|c|c|}
\hline Measurement Tool & Baseline & $\begin{array}{c}3 \text { Months (Post-Intervention) } \\
\text { Change }\end{array}$ & $P$ & $\begin{array}{l}\text { Subjects With Clinically Significant } \\
\text { Improvement* After Intervention (\%) }\end{array}$ \\
\hline mMRC (scale $0-4) \dagger$ & $2.4(1.0)$ & $-0.4(0.7)$ & .002 & 27.4 \\
\hline CRQ Dyspnea (scale 1-7)§ & $4.8(1.5)$ & $0.2(0.8)$ & .20 & 25.5 \\
\hline CRQ Fatigue (scale 1-7)§ & $4.0(1.3)$ & $0.5(0.9)$ & .001 & 33.3 \\
\hline CRQ Emotion (scale 1-7)§ & $5.0(1.1)$ & $0.4(0.7)$ & .001 & 31.4 \\
\hline CRQ Mastery (scale 1-7)§ & $5.1(1.2)$ & $0.3(0.9)$ & .007 & 33.3 \\
\hline GSRH (scale $1-5) \dagger$ & $3.7(0.9)$ & $-0.3(0.8)$ & .03 & 33.3 \\
\hline $\begin{array}{l}\text { * One point for mMRC and GSRH, ar } \\
\dagger \text { Lower value indicates best condition } \\
\S \text { Higher value indicates best conditio } \\
\text { mMRC = Modified Medical Research } \\
\text { CRQ = Chronic Respiratory Disease } \\
\text { GSRH = general self-rated health stat }\end{array}$ & int for CRQ. & llent, very good, good, fair or poor? & & \\
\hline
\end{tabular}

Table 2. Participant Descriptions of the Benefits of Coaching

\begin{tabular}{|c|c|}
\hline Theme of Responses & Representative Quote \\
\hline $\begin{array}{l}\text { Theme 1: Participants view coaching } \\
\text { conversations as motivating and } \\
\text { encouraging. }\end{array}$ & $\begin{array}{l}\text { To have someone there that calls you up and talks to you and encourages you to do things, } \\
\text { not push you, just encourage. It gives you a little bit more willpower to keep going and } \\
\text { try a little more all the time. } \\
\text { It seemed to boost me up a little bit. Give me a little more courage. It would make me } \\
\text { want to do it again. Do the exercise better. }\end{array}$ \\
\hline $\begin{array}{l}\text { Theme 2: Coaching conversations } \\
\text { increased accountability. }\end{array}$ & $\begin{array}{l}\text { Just the fact that come Thursday, I knew I would have to talk to [the coach] so I was } \\
\text { always cognizant of keeping up with some activity, as minor as it might be, and keeping } \\
\text { my activity log up-to-date and pedometer readings. } \\
\text { It's like anything else you do where somebody is motivating you or checking on you. You } \\
\text { pay a little more attention to what you are doing and you want to be able to report some } \\
\text { progress, so it's helpful in that regard. } \\
\text { They make sure you are doing what you are supposed to be doing.... I had somebody to } \\
\text { report to when I accomplished or didn't accomplish. }\end{array}$ \\
\hline $\begin{array}{l}\text { Theme 3: Through coaching, } \\
\text { participants gained increased } \\
\text { awareness of health and health } \\
\text { behavior. }\end{array}$ & $\begin{array}{l}\text { Probably made me more aware of what I'm doing and not doing, or what I should be } \\
\text { doing. It just reinforces to follow the guidelines. Try to do better, let's put it that way. } \\
\text { It certainly made me more aware of setting some goals. } \\
\text { Well, my general awareness of what I was doing. I became very aware of my activity } \\
\text { levels. } \\
\text { She gave me examples of alternative things that I could do. I guess she gave me the } \\
\text { insight for other things. } \\
\text { It keeps you mindful of what you are trying to do. }\end{array}$ \\
\hline
\end{tabular}

component of the Chronic Respiratory Disease Questionairre, as presented in Table 1. Twenty-three (45\%) participants continued to have improvement in at least 1 end point at the completion of study follow-up at 6 months.

\section{Post-Intervention Qualitative Assessment}

The participant descriptions on the benefits of coaching are described in Table 2. Several participants listed personal benefits of coaching that did not represent an overall theme, but did add additional support to the sense of acceptability of the intervention and those participants who valued coaching (eg, "I know the coach was not after me to diet, but that was part of my goal, too: I have lost between 10-15 pounds"; "It has helped my breathing"; "It kept my spirits up quite a bit"; and "I just feel like I am stronger: My leg muscles, my arms.").

\section{Discussion}

We found that health coaching is a feasible and acceptable intervention that, in this pilot study, produced substantial improvement in the perception of health status after intervention as measured by the Chronic Respiratory Disease Questionairre, GSRH, and, in dyspnea, by the mMRC dyspnea scale in subjects with moderate to severe COPD. Motivational interviewing-based health coaching has recently been considered beneficial in a randomized 


\section{Motivational Health Coaching in COPD}

study of subjects with severe COPD, often preventing rehospitalization. ${ }^{1}$ In this pilot study, we envisioned testing a similar intervention for individuals with stable COPD who otherwise could not access PR.

We found an increase (benefit) in Chronic Respiratory Disease Questionairre component scores of 0.2 to 0.5 points following intervention. A 0.5 -point change on a 7-point scale is considered a minimum clinically important difference. ${ }^{32} \mathrm{~A}$ meta-analysis done on studies comparing traditional PR with usual care showed that scores for each Chronic Respiratory Disease Questionairre domain improved 0.5 to 1.0 point, which is both statistically and clinically important. ${ }^{7}$ Our intervention had a smaller improvement but did reach the lower end of the range observed in this meta-analysis. The improvements in Chronic Respiratory Disease Questionairre domains found in this pilot fell within the range of results seen in several home PR studies. ${ }^{22,24}$ Importantly, the improvement in dyspnea and the Chronic Respiratory Disease Questionairre from our telephone-based health-coaching intervention was comparable with other studies implementing alternatives to conventional PR programs. ${ }^{19} \mathrm{We}$ believe our results are of particular interest because our recruitment was geared toward participants who could not otherwise access PR.

Our study also showed a clinically important improvement in a third of our subjects using GSRH, a measurement of global health that other groups found to be associated with mortality, hospitalizations, and health-care utilization. ${ }^{30,31}$ The improvement in a generalized health measurement provides reinforcement that our intervention had positive effects on subjects' overall health status.

Our study found a sustained improvement in dyspnea as measured by mMRC. Findings are comparable with a reported internet-based intervention. ${ }^{19}$ However, results of this study were opposite of other studies, with 1 using a telehealth intervention ${ }^{18}$ that did not show such a noticeable improvement in dyspnea as assessed by the St George Respiratory Questionnaire and another using health coaching-based behavioral intervention with no improvement in dyspnea as measured by the Chronic Respiratory Disease Questionairre. $^{33}$

\section{Limitations}

There were several limitations to our study. This was a pilot study with a small observational cohort and was not a randomized, controlled trial. Because of the nature of the study, with no in-person follow-up visits, we were not able to obtain a measurement of exercise capacity, such as a 6-min walk test. We experienced a dropout rate of $14 \%$ (participants not completing the intervention) that is comparable with prior studies. ${ }^{34}$ Lack of time and the inability to commit were commonly cited reasons for difficulty in recruiting participants. ${ }^{35}$ Participants with chronic disease showed a low level of adherence to treatment recommendations. ${ }^{36}$ We recognize that the improvement in the Chronic Respiratory Disease Questionairre was not meaningful in all participants (despite being substantial), but given the simplicity and low-cost nature of the intervention, we believe the limitation of the telephone health coaching is acceptable (particularly considering the lack of alternative programs to improve QOL in patients who do not have access to PR).

\section{Conclusions}

We found that a telephone health-coaching intervention based on motivational interviewing was feasible. The intervention was acceptable to participants with at least moderate COPD eligible for PR, and markedly improved dyspnea and critical aspects of health-related QOL for participants with COPD. This pilot study provides an insight into possible alternatives to conventional PR for patients with limited access to those programs.

\section{REFERENCES}

1. Benzo R, Vickers K, Novotny PJ, Tucker S, Hoult J, Neuenfeldt P, et al. Health coaching and chronic obstructive pulmonary disease rehospitalization: a randomized study. Am J Respir Crit Care Med 2016;194(6):672-680.

2. Jones PW, Brusselle G, Dal Negro RW, Ferrer M, Kardos P, Levy ML, et al. Health-related quality of life in patients by COPD severity within primary care in Europe. Respir Med 2011;105(1):57-66.

3. Bahadori K, FitzGerald JM. Risk factors of hospitalization and readmission of patients with COPD exacerbation - systematic review. Int J Chron Obstruct Pulmon Dis. 2007 Sep;2(3):241-251.

4. Domingo-Salvany A, Lamarca R, Ferrer M, Garcia-Aymerich J, Alonso J, Félez M, et al. Health-related quality of life and mortality in male patients with chronic obstructive pulmonary disease. Am J Respir Crit Care Med 2002;166(5):680-685.

5. Vestbo J, Hurd SS, Agusti AG, Jones PW, Vogelmeier C, Anzueto A, et al. Global strategy for the diagnosis, management, and prevention of chronic obstructive pulmonary disease: GOLD executive summary. Am J Respir Crit Care Med 2013;187(4):347-365.

6. Spruit MA, Singh SJ, Garvey C, ZuWallack R, Nici L, Rochester C, et al. An official American Thoracic Society/European Respiratory Society statement: key concepts and advances in pulmonary rehabilitation. Am J Respir Crit Care Med 2013;188(8):e13-e64.

7. Lacasse Y, Goldstein R, Lasserson TJ, Martin S. Pulmonary rehabilitation for chronic obstructive pulmonary disease. Cochrane Database Syst Rev 2006;(4):CD003793.

8. Finnerty JP, Keeping I, Bullough I, Jones J. The effectiveness of outpatient pulmonary rehabilitation in chronic lung disease: a randomized controlled trial. Chest 2001;119(6):1705-1710.

9. Güell R, Casan P, Belda J, Sangenis M, Morante F, Guyatt GH, Sanchis J. Long-term effects of outpatient rehabilitation of COPD: a randomized trial. Chest 2000;117(4):976-983.

10. Taylor R, Dawson S, Roberts N, Sridhar M, Partridge MR. Why do patients decline to take part in a research project involving pulmonary rehabilitation? Respir Med 2007;101(9):1942-1946.

11. Keating A, Lee A, Holland AE. What prevents people with chronic obstructive pulmonary disease from attending pulmonary rehabilitation? A systematic review. Chron Respir Dis 2011;8(2):89-99.

12. Keating A, Lee AL, Holland AE. Lack of perceived benefit and inadequate transport influence uptake and completion of pulmonary 


\section{Motivational Health Coaching in COPD}

rehabilitation in people with chronic obstructive pulmonary disease: a qualitative study. J Physiother 2011;57(3):183-190.

13. Young P, Dewse M, Fergusson W, Kolbe J. Respiratory rehabilitation in chronic obstructive pulmonary disease: predictors of nonadherence. Eur Respir J 1999;13(4):855-859.

14. Fischer MJ, Scharloo M, Abbink JJ, van 't Hul AJ, van Ranst D, Rudolphus A, et al. Drop-out and attendance in pulmonary rehabilitation: the role of clinical and psychosocial variables. Respiratory Med 2009;103(10):1564-1571.

15. Fan VS, Giardino ND, Blough DK, Kaplan RM, Ramsey SD. Costs of pulmonary rehabilitation and predictors of adherence in the National Emphysema Treatment Trial. COPD 2008;5(2):105-116.

16. Yohannes AM, Yalfani A, Doherty P, Bundy C. Predictors of dropout from an outpatient cardiac rehabilitation programme. Clin Rehabil 2007;21(3):222-229.

17. Ries AL, Kaplan RM, Myers R, Prewitt LM. Maintenance after pulmonary rehabilitation in chronic lung disease: a randomized trial. Am J Respir Crit Care Med 2003;167(6):880-888.

18. Stickland M, Jourdain T, Wong EY, Rodgers WM, Jendzjowsky NG, Macdonald GF. Using telehealth technology to deliver pulmonary rehabilitation in chronic obstructive pulmonary disease patients. Can Respir J 2011;18(4):216-220.

19. Nguyen HQ, Donesky D, Reinke LF, Wolpin S, Chyall L, Benditt $\mathrm{JO}$, et al. Internet-based dyspnea self-management support for patients with chronic obstructive pulmonary disease. J Pain Symptom Manage 2013;46(1):43-55.

20. Pradella CO, Belmonte GM, Maia MN, Delgado CS, Luise AP, Nascimento OA, et al. Home-based pulmonary rehabilitation for subjects with COPD: a randomized study. Respir Care 2015;60(4): 526-532.

21. Holland AE, Mahal A, Hill CJ, Lee AL, Burge AT, Cox NS, et al. Home-based rehabilitation for COPD using minimal resources: a randomized, controlled equivalence trial. Thorax 2016;72(1):57-65.

22. Maltais F, Bourbeau J, Shapiro S, Lacasse Y, Perrault H, Baltzan M, et al. Effects of home-based pulmonary rehabilitation in patients with chronic obstructive pulmonary disease: a randomized trial. Ann Intern Med 2008;149(12):869-878.

23. Hospes G, Bossenbroek L, Ten Hacken NH, van Hengel P, de Greef $\mathrm{MH}$. Enhancement of daily physical activity increases physical fitness of our clinic COPD patients: results of an exercise counseling program. Patient Educ Couns 2009;75(2):274-278.

24. Vieira DS, Maltais F, Bourbeau J. Home-based pulmonary rehabilitation in chronic obstructive pulmonary disease patients. Curr Opin Pulm Med 2010;16(2):134-143.
25. Moy ML, Collins RJ, Martinez CH, Kadri R, Roman P, Holleman $\mathrm{RG}$, et al. An internet-mediated pedometer-based program improves health-related quality-of-life domains and daily step counts in COPD: a randomized controlled trial. Chest 2015;148(1):128-137.

26. Benzo R, Vickers K, Ernst D, Tucker S, McEvoy C, Lorig K. Development and feasibility of a self-management intervention for chronic obstructive pulmonary disease delivered with motivational interviewing strategies. J Cardiopulm Rehabil Prev 2013;33(2):113123.

27. Long K, Holman H, Sobel D, Laurent D, González V, Minor M. Living a healthy life with chronic conditions, 4th edition. Boulder, CO: Bull Publishing Company; 2012.

28. Bestall JC, Paul EA, Garrod R, Garnham R, Jones PW, Wedzicha JA. Usefulness of the Medical Research Council (MRC) dyspnoea scale as a measure of disability in patients with chronic obstructive pulmonary disease. Thorax 1999;54(7):581-586.

29. Aaron SD, Vandemheen KL, Clinch JJ, Ahuja J, Brison RJ, Dickinson G, Hebért PC. Measurement of short-term changes in dyspnea and disease-specific quality of life following an acute COPD exacerbation. Chest 2002;121(3):688-696.

30. DeSalvo KB, Fan VS, McDonell MB, Fihn SD. Predicting mortality and healthcare utilization with a single question. Health Serv Res 2005;40(4):1234-1246.

31. Nguyen HQ, Donesky-Cuenco D, Carrieri-Kohlman V. Associations between symptoms, functioning, and perceptions of mastery with global self-rated health in patients with COPD: a cross-sectional study. Int J Nurs Stud 2008;45(9):1355-1365.

32. Kupferberg DH, Kaplan RM, Slymen DJ, Ries AL. Minimal clinically important difference for the UCSD Shortness of Breath Questionnaire. J Cardiopulm Rehabil 2005;25(6):370-377.

33. Coultas DB, Jackson BE, Russo R, Peoples J, Sloan J, Singh KP, et al. A lifestyle physical activity intervention for patients with COPD: a randomized controlled trial. Ann Am Thorac Soc 2016;13(5):617626.

34. Cambach W, Chadwick-Straver RV, Wagenaar RC, van Keimpema AR, Kemper HC. The effects of a community-based pulmonary rehabilitation programme on exercise tolerance and quality of life: a randomized controlled trial. Eur Respir J 1997;10(1):104-113.

35. Faulkner J, Walshaw E, Campbell J, Jones R, Taylor R, Price D, Taylor AH. The feasibility of recruiting patients with early COPD to a pilot trial assessing the effects of a physical activity intervention. Prim Care Respir J 2010;19(2):124-130.

36. O’Donohoe R, Fullen BM. Adherence of subjects with cystic fibrosis to their home program: a systematic review. Respir Care 2014;59(11): 1731-1746. 